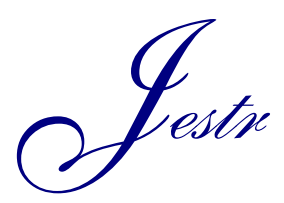

Journal of Engineering Science and Technology Review 6 (1) (2013) 87 -90

JOURNAL OF

Engineering Science and

Technology Review

Research Article

M/MMM iectr nro

\title{
Determination of the Optimal Tilt Angle for Solar Photovoltaic Panel in Ilorin, Nigeria
}

\author{
K.R. Ajao*, R.M. Ambali and M.O. Mahmoud \\ Department of Mechanical Engineering, University of Ilorin, Ilorin, Nigeria
}

Received 3 April 2013; Accepted 25 June 2013

\begin{abstract}
The optimal tilt angle of solar photovoltaic panel in Ilorin, Nigeria was determined. The solar panel was first mounted at $0 \mathrm{o}$ to the horizontal and after ten minutes, the voltage and current generated with the corresponding atmospheric temperature were recorded. The same procedure was repeated for 20 to $30 \mathrm{o}$ at a succession of $2 \mathrm{o}$ at ten minutes time interval over the entire measurement period. The result obtained shows that the average optimal tilt angle at which a solar panel will be mounted for maximum power performance at fixed position in Ilorin is 22o. This optimum angle of tilt of the solar panel and the orientation are dependent on the month of the year and the location of the site of study.
\end{abstract}

Keywords: solar photovoltaic, optimal tilt angle, maximum power, solar panel orientation, site of study

\section{Introduction}

The demand for electricity to meet the need of the society is increasing at an alarming rate in most countries of the world, especially in Nigeria. To meet these needs, many Nigerians are now seeking alternative sources of energy besides the rapidly depleting and polluting fossil fuels that the current infrastructure has become dependent upon.

The use of solar energy (photovoltaic) to meet residential energy needs has been promoted for some years now in Nigeria by some renewable energy companies [1]. This was due to the numerous advantages that solar energy has compared to fossil fuels. Solar energy is the energy produced directly by the sun in form of radiation and captured on earth for practical ends especially for generation of electricity.

Ilorin has an annual average solar radiation of about 5.0 $\mathrm{kWh} / \mathrm{m}^{2} /$ day according to the radiation contour map of Nigeria [1]. This shows that Ilorin is a very suitable area for harnessing this free source of energy and this resource should be utilized effectively for the benefit of those residing in this particular location and its environs.

Solar energy can be converted into electricity directly using photovoltaic (PV) solar module which converts sunlight into electricity using photoelectric effect. However, the performance of the photovoltaic module depends on the light intensity of the sun which in turns depends on the weather condition and the orientation of the solar panel.

Apart from the two factors mentioned above, the performance of a solar panel also depends on a very important factor called the optimal tilt angle. This is an angle at which the solar panel should be positioned with the horizontal plane to generate maximum power. The angle is dependent on the latitude of the particular site of installation and the season of installation of the solar panel.

*E-mail address: ajaomech@unilorin.edu.ng

ISSN: 1791-2377 (C) 2013 Kavala Institute of Technology. All rights reserved.
As important as this factor may be, it was discovered that most solar panels currently installed in different locations in Ilorin metropolis especially for street lighting, were tilted at different angles and facing different directions. This contributed to the reduction of the amount of energy that should have been be captured from the sun to generate maximum power thereby constituting great economic loss.

\section{Solar Energy}

Solar energy is one of the renewable sources of energy well investigated to be capable of meeting the needs of the society when the fossil fuels are finally exhausted.

At its core, solar energy is actually a nuclear energy. In the inner $25 \%$ of the Sun, hydrogen is fusing into helium at a rate of about $7 \times 10^{11} \mathrm{~kg}$ of hydrogen every second but the sun has enough hydrogen in the core to continue at this rate for another five billion years [2]. This is an indication that solar energy will always be available for the benefit of mankind even if fossil fuel is no more available for human consumption.

The sun radiates $3.85 \times 10^{26}$ joules of energy every second, a value which is more than the total energy man has ever used since creation. Although some of this energy is lost in the atmosphere, the amount reaching the earth's surface every second, if properly harnessed is still probably enough energy to meet the world's energy demand. The only restrictions of solar energy are weather condition, time of the day which makes it not constantly available on earth. Thus some form of storage device is needed to sustain a solar power system through the night periods when local weather conditions obscure the sun [3].

It was reported that about $80 \%$ of the world's oil reserves have been consumed by 1980 at the rate of the world energy consumption in 1975 . The remaining reserves of coal in the world is estimated to last for about 25 years, 
while the life expectancy of the oil and gas reserves in the world is not positively known [3].

Of all the energy sources available, solar has perhaps the most promise. Numerically, it is capable of producing the raw power required to satisfy the entire planet's energy needs. Environmentally, it is one of the least destructive of all the sources of energy. Practically, it can be adjusted to power nearly everything except transportation with very little adjustment, and even transportation with some modest modification to the current general system of travel [4].

The current and power output of photovoltaic modules is approximately proportional to the sunlight intensity. This implies that the efficiency of solar panel depends on the weather condition, time of the day and the site of installation of the system. Consideration of the site of installation brings about installing a solar panel in a place where it will be able to capture enough sunlight [4].

PV modules are very sensitive to shading. If a tree branch, roof vent, chimney or other item is shading from a distance, the shadow is diffused or dispersed. This significantly reduces the amount of light reaching the cells of a module. Other sources are those that stop light from reaching the solar cells, such as a blanket, tree branch, bird dropping etc. If one full cell is shaded, the voltage of that module will drop to half of its un-shaded value in other to protect itself. If enough cells are shaded, the module will not convert any energy and will in fact become a tiny drain of energy on the entire system [4]. This connotes the importance of installing a solar panel in an open space where it will be free from any shadow or obstruction no matter how small it may be. It also implies that the surface of the panel must be free from any dirt for efficient capturing of sunlight by the solar panel.

According to Stefan-Boltzmann's law, the amount of energy that is radiated per unit area of surface depends upon the temperature of the object to the fourth power. This implies that the amount of energy that is emitted by the sun is very much dependent upon the surface temperature.

Solar panel temperature is one of the important factors that affect how much electricity a solar panel will produce. It is ironic, but the more sunshine available get, the hotter the panels get and this in turn counteracts the benefit of the sun [5]. High temperature reduces solar panel efficiency and hence, a solar panel system has to be designed in such a way that it will allow air circulation around the solar panel to cool it.

\subsection{Optimal Tilt Angle}

At any given instant, solar panel will generate maximum output when pointed directly at the Sun. The optimal tilt angle is perpendicular to the Sun's rays at true solar noon [6]. True solar noon is when the Sun is at its highest during its daily East-West path across the sky known as $0^{0}$ Azimuth.

In order to capture the maximum amount of solar radiation, the tilt angle should be adjusted seasonally at $15^{0}$ more than the latitude angle [6].

\section{Methodology}

The experiment carried out between May and June, 2012 was setup using a $200 \mathrm{~W}$ rated solar panel, a solar panel mount, two digital multimeters (one measures voltage while the other measures current), a digital clock capable of measuring ambient temperature, a luxmeter and two incandescent bulbs(as direct current load). The voltage and power of the incandescent bulbs were $24 \mathrm{~V}$ and $21 \mathrm{~W}$ respectively.

For countries in the northern hemisphere, solar panels should always face true south.The solar panel was mounted in an open space and in such a way that it can be tilted from $0^{\circ}$ to $30^{\circ}$ to the horizontal and was faced towards the south. The two incandescent bulbs were connected to the output terminals of the solar panel using a connector and the two multimeters were used to measure the voltage and current generated by the solar panel. A digital clock capable of measuring atmospheric temperature and a luxmeter were in place for timing and to measure the ambient temperature and light intensity incident on the solar panel corresponding to a particular angle respectively.

The solar panel was first mounted at $0^{\circ}$ to the horizontal for ten minutes and the voltage and current generated with the corresponding atmospheric temperature were recorded. The same procedure was repeated from $2^{\circ}$ to $30^{\circ}$ at a succession of $2^{\circ}$ with ten minutes time interval. Data for ten best sunny days over the measurement period was analysed and used to establish the optimal tilt angle of solar panel in Ilorin.

Before the solar panel assembly was installed, an engineering prismatic compass was used to determine the cardinal position of the solar panel to ensure that it was truly facing south as shown in Figure 1. The open circuit voltage test was performed with a digital multimeter and the value of the open circuit voltage was read to be $57.7 \mathrm{~V}$ which was very close to $57.8 \mathrm{~V}$ on the name plate. The value of the short circuit current was also read to be $4.78 \mathrm{~A}$.

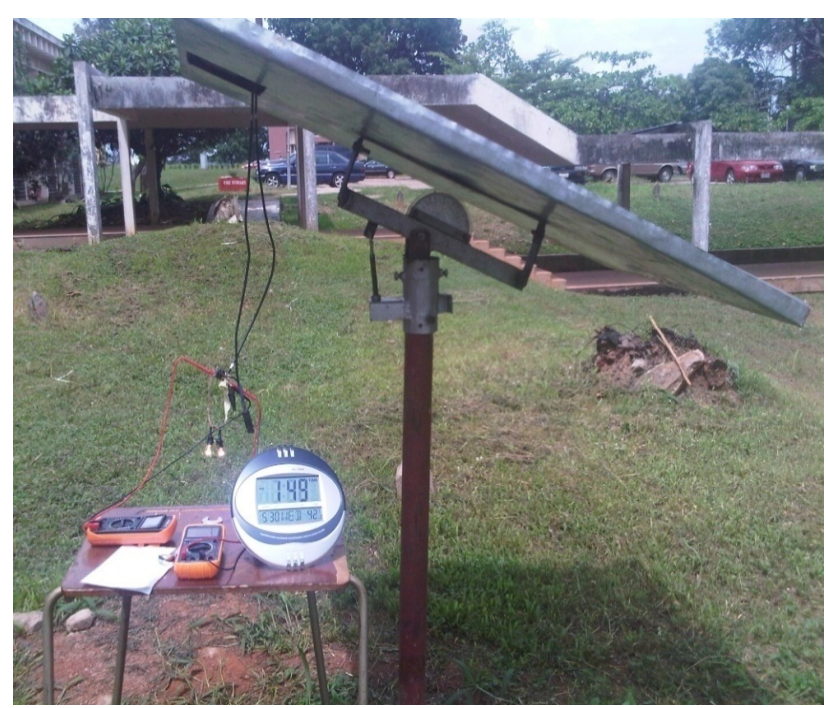

Fig. 1. Optimal tilt angle measurement for solar panel

\section{Results and Discussion}

Tables 1 and 2 below give the result of the current, voltage and power generated by a solar panel at an inclination angle ranging from $0^{\circ}$ to $30^{\circ}$ at an interval of $2^{\circ}$ and the corresponding temperature and light intensity in selected sunny days over the measurement period.

With the solar panel orientated towards south and inclined from $0^{\circ}$ to $30^{\circ}$ at a succession of $2^{\circ}$ and at ten minutes time interval, the power generated and the corresponding temperature were recorded. Figure 2 shows the graph of power generated by the solar panel at different 
angle of inclination on Day 1 while Figure 3 shown the graph of the power generated on Day 10.

Table 1. Data obtained on Day 1

\begin{tabular}{ccccc}
\hline $\begin{array}{c}\text { Angle } \\
\left.\mathbf{\Theta} \mathbf{(}^{(}\right)\end{array}$ & $\begin{array}{c}\text { Temperature } \\
\left({ }^{\circ} \mathbf{C}\right)\end{array}$ & $\begin{array}{c}\text { Current } \\
\mathbf{I}(\mathbf{A})\end{array}$ & $\begin{array}{c}\text { Voltage } \\
(\mathbf{V})\end{array}$ & $\begin{array}{c}\text { Power } \\
(\text { Watt })\end{array}$ \\
\hline $\mathbf{0}$ & 35.3 & 0.80 & 45.8 & 36.64 \\
$\mathbf{2}$ & 35.3 & 0.81 & 47.7 & 38.64 \\
$\mathbf{4}$ & 40.6 & 0.82 & 48.0 & 39.36 \\
$\mathbf{6}$ & 37.4 & 0.81 & 47.6 & 38.56 \\
$\mathbf{8}$ & 37.0 & 0.75 & 41.6 & 31.20 \\
$\mathbf{1 0}$ & 32.7 & 0.77 & 42.7 & 32.88 \\
$\mathbf{1 2}$ & 35.5 & 0.81 & 47.6 & 38.56 \\
$\mathbf{1 4}$ & 38.0 & 0.79 & 45.4 & 35.87 \\
$\mathbf{1 6}$ & 36.6 & 0.81 & 47.8 & 38.72 \\
$\mathbf{1 8}$ & 42.7 & 0.80 & 47.1 & 37.68 \\
$\mathbf{2 0}$ & 40.1 & 0.79 & 45.7 & 36.10 \\
$\mathbf{2 2}$ & 42.5 & 0.81 & 47.8 & 38.72 \\
$\mathbf{2 4}$ & 40.0 & 0.78 & 44.6 & 34.79 \\
$\mathbf{2 6}$ & 36.3 & 0.77 & 42.8 & 32.96 \\
$\mathbf{2 8}$ & 36.5 & 0.76 & 42.0 & 31.92 \\
$\mathbf{3 0}$ & 36.5 & 0.76 & 41.8 & 31.77 \\
\hline
\end{tabular}

Table 2. Data obtained on Day 10

\begin{tabular}{cccccc}
\hline $\begin{array}{c}\text { Angle } \\
\boldsymbol{\Theta}\left({ }^{\circ}\right)\end{array}$ & $\begin{array}{c}\text { Tempe- } \\
\text { rature } \\
\left({ }^{\circ} \mathbf{C}\right)\end{array}$ & $\begin{array}{c}\text { Light } \\
\text { Intensity } \\
(\mathbf{L u x})\end{array}$ & $\begin{array}{c}\text { Current } \\
\mathbf{I}(\mathbf{A})\end{array}$ & $\begin{array}{c}\text { Voltage } \\
(\mathbf{V})\end{array}$ & $\begin{array}{c}\text { Power } \\
(\text { Watt) }\end{array}$ \\
\hline $\mathbf{0}$ & 35.7 & 660 & 0.80 & 48.5 & 38.80 \\
$\mathbf{2}$ & 36.0 & 732 & 0.80 & 47.8 & 38.24 \\
$\mathbf{4}$ & 40.5 & 1334 & 0.81 & 48.8 & 39.53 \\
$\mathbf{6}$ & 42.7 & 392 & 0.77 & 44.3 & 34.11 \\
$\mathbf{8}$ & 40.5 & 797 & 0.78 & 46.3 & 36.11 \\
$\mathbf{1 0}$ & 36.2 & 426 & 0.78 & 45.6 & 35.57 \\
$\mathbf{1 2}$ & 40.2 & 887 & 0.79 & 46.5 & 36.74 \\
$\mathbf{1 4}$ & 42.0 & 541 & 0.77 & 44.7 & 34.42 \\
$\mathbf{1 6}$ & 42.0 & 303 & 0.75 & 42.0 & 31.50 \\
$\mathbf{1 8}$ & 36.0 & 501 & 0.78 & 46.2 & 36.04 \\
$\mathbf{2 0}$ & 40.4 & 1403 & 0.80 & 48.6 & 38.88 \\
$\mathbf{2 2}$ & 36.0 & 526 & 0.79 & 46.5 & 36.74 \\
$\mathbf{2 4}$ & 40.1 & 479 & 0.77 & 45.0 & 34.65 \\
$\mathbf{2 6}$ & 36.6 & 277 & 0.77 & 44.5 & 34.27 \\
$\mathbf{2 8}$ & 35.0 & 138 & 0.67 & 33.7 & 22.58 \\
$\mathbf{3 0}$ & 35.2 & 104 & 0.53 & 21.2 & 11.24 \\
\hline
\end{tabular}

The results obtained from the experiment shown in the Figures $2 \& 3$ above indicate that there was no constant optimal tilt angle for all the ten days sampled. Thus, the average of the powers generated by each of the tilt angles had to be computed.

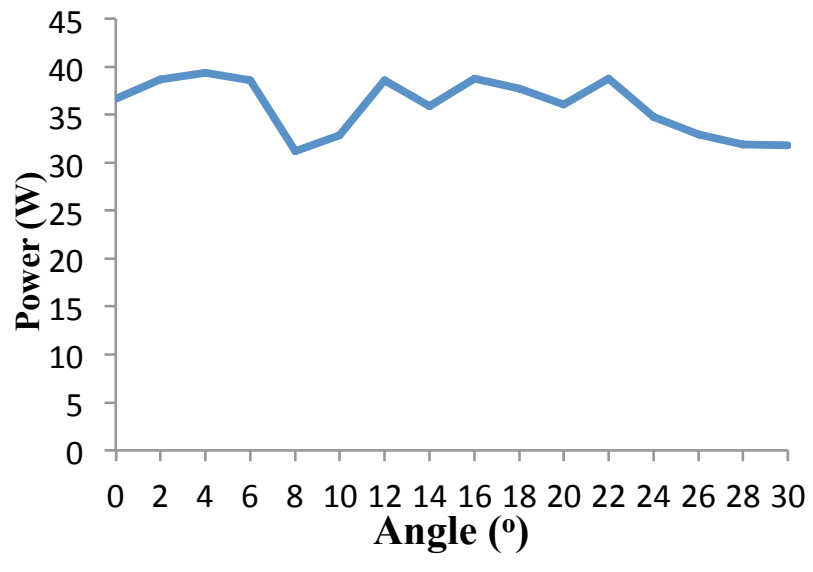

Fig. 2. Power generated by a solar panel from

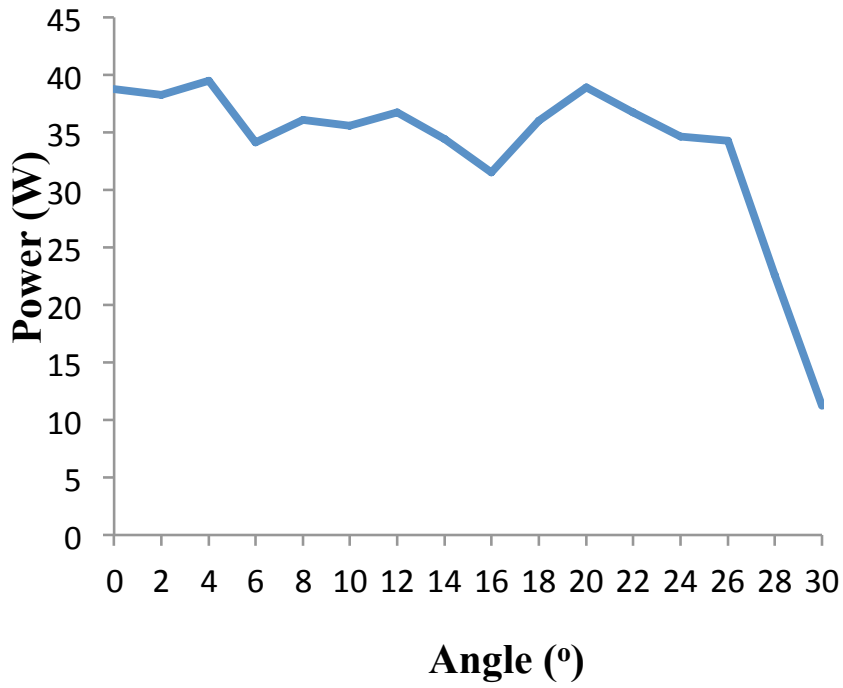

Fig. 3. Power generated by a solar panel from $0^{\circ}$ to $30^{\circ}$ for Day 10

Table 3. Average power at each tilt angle

\begin{tabular}{cc}
\hline $\begin{array}{c}\text { Angle } \\
\boldsymbol{\Theta}\left({ }^{\circ}\right)\end{array}$ & $\begin{array}{c}\text { Average Power } \\
(\text { Watt) }\end{array}$ \\
\hline $\mathbf{0}$ & 37.12 \\
$\mathbf{2}$ & 37.19 \\
$\mathbf{4}$ & 37.93 \\
$\mathbf{1 2}$ & 37.72 \\
$\mathbf{1 8}$ & 37.67 \\
$\mathbf{2 2}$ & 38.02 \\
$\mathbf{2 4}$ & 37.31 \\
$\mathbf{2 6}$ & 37.16 \\
$\mathbf{2 8}$ & 35.92 \\
$\mathbf{3 0}$ & 34.88 \\
\hline
\end{tabular}




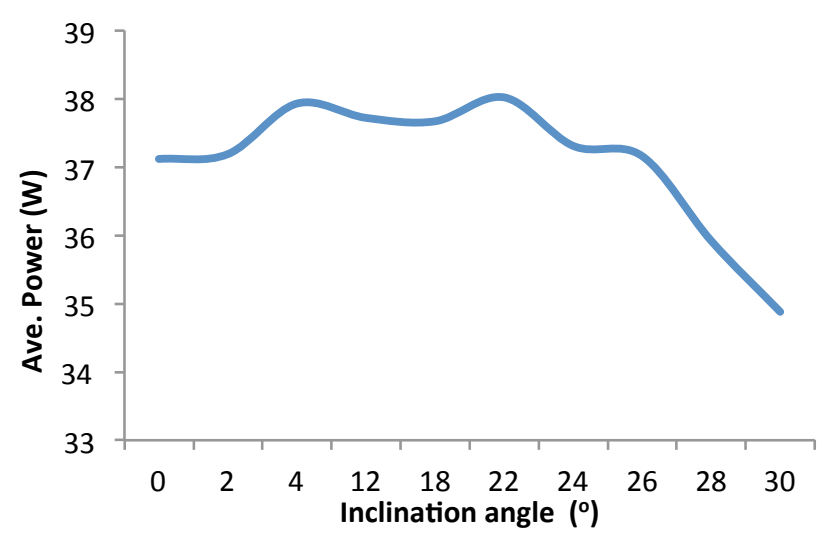

Fig. 4. Graph showing the optimum inclination angle

The result depicted in Table 3 and Figure 4 shows that the maximum average power generated was $38.02 \mathrm{~W}$ which corresponds to inclination angle of $22^{\circ}$. It can therefore be concluded that $22^{\circ}$ is the optimal tilt angle for solar panel in Ilorin as determined by this experiment. This was in contrast to $14^{0}$ optimal tilt angle obtained for Ilorin by using the Photovoltaic Geographical Information System (PVGIS) software. It is also necessary to note that the PVGIS software did not specify whether the season for the optimal tilt angle given is winter or summer period.

According to the recommendation made by some researchers, the optimal tilt angle of solar panel during winter is the latitude of the site of installation plus $15^{\circ}$. Hence, the optimal tilt angle of a solar panel in Ilorin could be $\left(8.5^{\circ}+15^{\circ}\right)$ or $23.5^{\circ}$ which is very much closer to the value obtained from the experiment carried out.

\section{Conclusion}

The study to determine the optimal tilt angle for solar photovoltaic system in Ilorin, Nigeria was carried out. The result shows that the tilt angle at which the solar panel generated maximum power out was $22^{\circ}$.

The power generated by a solar panel is dependent on the angle at which it is tilted, the prevailing weather condition and the orientation of the solar panel. Improper orientation of the solar panel would eventually lead to loss in power and poor return on investment.

For maximum energy gain, solar panels should be inclined at optimal tilt angle and seasonal adjustment of the panel may lead to considerable gain in power obtained from solar energy.

\section{References}

1. Olorunmaiye J.A. "Energy Conversion and Man" $106^{\text {th }}$ Inaugural Lecture Delivered before the University of Ilorin on $24^{\text {th }}$ May, 2012

2. Alternative Energy: Solar Energy, available online at:http://esa21.kennesaw.edu/activities/solar/solaractivity.pdf. Accessed on 25th June, 2012.

3. Babatunde E.B., "Solar Energy, A Friendly Renewable Energy Source", available online: http://www.intechopen.com/books/solarradiation/solar-radiation-a-friendly-renewable-energy-source. Accessed on 29th June, 2012.
4. Eric W. B., "An Introduction to Solar Energy", available online: http://citeseerx.ist.psu.edu/viewdoc/download?doi=10.1.1.69.1112 \&rep=rep1\&typ=pdf. Accessed on $25^{\text {th }}$ June, 2010.

5. Solar Panel Temperature Facts \& Tips, available Online: http://www.solar-facts-and-advice.com/solar-paneltemperature.html Accessed on 29th June, 2012.

6. Wholesale Solar, "Get the most Power out of your Solar Electric Panels", available online: www.wholesalesolar.com . Accessed on $20^{\text {th }}$ December, 2012. 